Uşak Üniversitesi Sosyal Bilimler Dergisi

$2015,8 / 3$

\title{
İlkokul Öğrencileri İçin Web Tabanlı Değerler Eğitimi Uygulaması
}

\author{
Kemal KARAMAN \\ İlker AKGÜL
}

\section{Öz}

$\mathrm{Bu}$ araştırmanın amacı, ilkokul öğrencileri için değerler eğitiminin öğretiminde ve kazandırılmasında alternatif bir yöntem-teknik olarak Web Tabanlı Değerler Eğitimi (WTDE) uygulamasının etkililiğini belirlemektir. Çalışmada, araştırmacılar tarafından değerler eğitiminin adalet ve dürüstlük olarak iki alt boyutunu temel alan bir uygulama ortamı geliştirilmiştir.

Araştırmanın çalışma grubunu, İstanbul ilinde üst, orta ve alt sosyoekonomik düzey çocukların öğrenim gördügü bir devlet okulundaki 4 . sınıftaki 10 ilkokul öğrencisi oluşturmuştur. Katılımcılar 12 hafta boyunca WTDE uygulama ortamına alınarak ilgili modelleri tamamlamışlardır. Araştırmada WTDE programının sürecini betimlemek ve kullanılabilirliğini incelemek amacıyla nicel ve nitel araştırma yöntemleri birlikte kullanılmıştır. Çalışmada veri toplama aracı olarak; "Görev Değerlendirme Kontrol Listesi", "Değerlerle İlgili İkilem Formu" ve "Yarı Yapılandırılmış Görüşme Formu" kullanılmıştır. Nicel kısımda "Değerlerle İlgili İkilem Formu" kullanılarak, öntest-sontest deney gruplu yarı-deneysel yöntem kullanılmıştır. Nitel kısımda ise "Yarı Yapılandırılmış Görüşme Formu" ile "Görev Değerlendirme Kontrol Listesi" kullanılarak veriler içerik analizi ve görev analizi ile betimlenmiştir.

Çalışma sonunda, Web Tabanlı Değerler Eğitimi (WTDE) uygulamasının, dürüstlük ve adalet değerini kazandırmada alternatif bir yöntem olabileceği sonucuna ulaşılmıştır. Ayrıca WTDE' nin bireylerin var olan adalet ve dürüstlük değerleri üzerinde etkisi olduğu bulunmuş, geliştirilen ortamın değer eğitimi için alternatif bir ortam olabileceği sonucuna ulaşılmıştır.

Anahtar Kelimeler: Değerler Eğitimi, Web Tabanlı Değerler Eğitimi, Dürüstlük, Adalet.

* Yrd. Doç. Dr., Uşak Üniversitesi, İletişim Fakültesi 


\title{
Web-based Ethical Values Education Application for Primary School Students
}

\begin{abstract}
The purpose of this study is to examine the effectiveness of the Webbased Ethical Values Education (WEVE) model as an alternative method in teaching and gaining ethical values and to bring this model in to our education. In this context web-based environment has been developed by the researchers in this study based on two sub-dimensions of ethical values education namely fairness and honesty.

The study group of this research consisted of 10 students who are at the 4th grade of a public primary school in which students from upper, middle and low social economic classes and located in Istanbul. Those attendees have completed related models by being taken into the WEVE application environment for 12 weeks.

In this research, quantitative and qualitative research methods were used to describe the WEVE process and to examine the usability of WEVE environment. By making use of "Dilemma Form about Ethical Values" (which is a quantitative research method), semi-experimental method which is based on a pattern with pre-test/pro-test experimental group is used. By making use of "Semi-Structured Meeting Form" and "Scale of Assignment Evaluation" (which are qualitative research methods), data is explained with descriptive analysis.

"Scale of Assignment Evaluation", "Dilemma Form about Ethical Values" and "Semi-Structured Meeting Form" are used as data collection tool in the study.

As a result of this research, we've achieved that Web-based Ethical Values Education application can be an alternative method to make people gain honesty and fairness values. Besides, it's discovered that WEVE has an effect on existing fairness and honesty values of people and this environment can be an alternative environment for ethical values education.
\end{abstract}

Key Words: Ethical Values Education, Web-based Ethical Values Education, Honesty, Fairness.

\section{Giriş}

Bireylere toplumca kabul edilen değerlerin kazandırılmasında toplumdaki kurumların çeşitli rol ve sorumlulukları vardır. Bu noktada aile ve okula önemli görevler düşmektedir. 
Sosyal Bilimler Dergisi 89

Okullarımız artık sadece akademik başarıya önem veren kurumlar değil, çağdaş hayatın ve insanlığın önem verdiği dürüstlük, adalet, saygılı olma, temizlik vb. kavramlara önem vererek, öğrencilerin bu kavramları kazanıp davranışa dönüştürmesi konusunda çok önemli bir yere sahiptir (Aydın ve Akyol, 2012). Bu nedenle değerler eğitimi, eğitimin en önemli amaçlarından biridir. Burada, bireyin önemini ortaya koyan uzun vadeli çalışmalar ve uygulamalar yapılmalıdır (Çağlayan, 2013). Son zamanlarda Milli Eğitim Bakanlığı bünyesinde, çerçeve planlar düzenlenerek değerler eğitimi ön plana çıkmıştır.

Değerler eğitimi, toplumsal hayatı etkileyen, bilgi, beceri ve tutumları kazandırmak amacıyla yapılan etkinlikleri kapsayan terimdir (Ekşi ve Katılmış, 2011). Değerler eğitimi, bireylerin sahip oldukları değerlerin farkına varıp, doğruluk, adalet, sevgi, saygı gibi bireylerin ve toplumun yaşantısını anlamlı kılmayı sağlayan değerleri kazanıp, benimseme ve davranışa dönüştürme sürecidir (Çağlayan, 2013; Yaman, 2012).

Okullarda verilen değerler eğitiminin sağlıklı ve istenilen düzeyde olması beklenir (Gündaş, Kurtulmuş ve Tösten, 2014). Değerler eğitimi, toplumun önemsediği değer ve davranışların kazandırılması sürecinde, okulların rolü ve önemi yadsınmamakla birlikte, okullarda bu sürece en önemli katkıyı eğiticiler sağlamaktadırlar. Yani değerler eğitimi için eğiticiler tarafından alternatif yöntem, teknik ve uygulamalar geliştirilmelidir.

Millî Eğitim Bakanlığı, değerler eğitimi konusunun, okullarda nasıl yürütüleceğine dair bir genelge yayımlayarak, değerler eğitimi konusuna verdiği önemi ortaya koymuş, hem de yapılabilecek etkinlik örneklerini belirtmiştir. Bu etkinlikleri organize etme ve rehberlik görevini ise, eğiticilere bırakmıştır. Önerilen bu etkinlik örneklerinden birisi de değerler eğitimi konusunda WEB ortamlarının oluşturulmasıdır (MEB, 2010).

Web Tabanlı Eğitim, internet üzerinden erişimi sayesinde, dinamik bir yapıya sahip olup, öğrenci ders kapsamını genişletebilme imkânıyla, araştırmalar yapabilmektedir. Böyle ortamlar, öğrenme-öğretme sürecinde etkililiği artırmaktadır (Baltacı, M. ve Akpınar, B. 2011; Yeniad, 2006). Bu ortam öğrencilerin sistem içerisinde aktif olmalarını, web ortamından belirlenen hedefler doğrultusunda faydalanmalarını sağlamaktadır.

İlgili alan çalışmalarına baktığımızda, değerler eğitimi ve web tabanlı eğitim uygulamalarının etkililiği ve önemini açıklayan çalışmaların yapıldığı görülmektedir.

Baltacı ve Akpınar (2011) ile Erdemir ve İngeç Kandil (2014) yaptıkları çalışmada web tabanlı eğitimin öğrencilerin akademik başarılarına katkı sağladığı, geleneksel yöntemlere göre daha etkili olduğu, Tüysüz ve 
Aydın (2007) yaptıkları araştırmada derslere karşı tutumlarının geleneksel yöntemlerle kıyaslandığında web tabanlı eğitim ortamlarında daha olumlu sonuçlar ortaya çıktığı, Oral ve Kenanoğlu (2012) çalışmalarında web tabanlı eğitim ortamlarının öğrencilerin derslerde gösterdikleri başarılarına olumlu etki sağladığı, öğrenmelerinin kalıcılığı üzerinde olumlu katkılar sağladığı ve öğrencilerin bilgisayara yönelik olumlu tutum geliştirdikleri sonuçlarına ulaşmışlardır.

Oladipo'ya (2009) göre eğitim sisteminin tek düzelikten çok yönlüye döndüğü, ahlaki eğitimin de bu değişimden olumlu etkilendiği, eğitimde yapılan reformların ahlak eğitiminde de büyük değişimler meydana getirmiştir. Sanderse (2012), ahlaki eğitimine katkı sağlamanın en önemli yollarından birinin öğretmenlerin çocuklara ahlaki davranışlarda örnek olmaları ve ahlaklı davranmanın önemini anlatmaları gerektiğini belirtmiştir.

Aslan (2011) yaptığı çalışmada öğretmen, öğrenci ve veli görüşlerine bakıldığında en çok tercih edilen on değerin sekizinin ortak olduğunu, bunların da; dürüstlük, sorumluluk, güvenilir olma, vatansever olma, büyüklere saygılı olma, azimli olma, çalışkan olma ve özsaygı olduğunu belirtmiştir. Moğul (2012) "Safahat" adlı eserde bilimsellik, çalışkanlık ve bağımsızlık değerlerinden sıkça bahsedildiği, bu eserin Türkçe eğitimi için uygun olacağı ve değerler eğitimi için de tüm değerler için geçerli olmasa da kullanılabilir olduğunu belirtmiştir. Öğretici (2011) yaptığı çalışmada sosyal bilgiler dersinde uygulanan duyarlılık ve sorumluluk değerleriyle ilgili yapılan uygulamaların bu değerlere ilişkin farkındalığı arttırdığı, bunun yanı sıra değerler eğitimi uygulamalarının yetersiz olduğu, alana ilgili katkılar sağlanması gerektiğini belirtmiştir.

Bu bağlamda, bu çalışmada ilkokul öğrencileri için değerler eğitimini öğretmede ve kazandırmada kullanılabilecek bir uygulama olarak Web Tabanlı Değerler Eğitimi ortamı geliştirmek ve bu ortamın değerler eğitiminde yer alan dürüstlük ve adalet değerlerini kazandırmada etkililiğini belirlemek amaçlanmıştır.

\section{Web Tabanlı Değerler Eğitimi Uygulaması Özellikleri}

WTDE uygulaması www.ilkerakgul.com adlı sitede uygulanmıştır. Öncelikle kullanıcıların sisteme girdiklerinde onları karşılayacak bir ara yüz geliştirilmiştir. $\mathrm{Bu}$ ara yüzde bir logo, slogan, değerlerin içeriklerine girebilecekleri menü, site ile ilgili üst menüler oluşturulmuştur. Öğrenciler sisteme girdiklerinde, sistemin tema rengini belirleyebilmektedirler. $\mathrm{Bu}$ da site giriş ekranını öğrencilerin kişiselleştirmelerini sağlamıştır. Basit bir uygulama gibi görünse de öğrencilerin hazır verilen bir ortamda ufak 
Sosyal Bilimler Dergisi 91

değişiklikler yapabilmeleri kendilerine ayrıcalık sağlanma hissini uyandırmıştır.

Sisteme girmek için öğrencilere birer kullanıcı adı ve şifre verilmiş. Belirlenen zaman diliminde öğrencilerin sisteme girişleri sağlanmıştır. Hazırlanan site, günlük hayatta sürekli kullanılan masaüstü-dizüstü bilgisayar, tablet ve mobil cihazlar üzerinden rahatlıkla çalışabilmektedir. Bu avantajda öğrencilerin sabit bir araçtan faydalanma yerine, farklı araçlardan da yararlanmalarını sağlamıştır.

Uygulama Dürüstlük ve Adalet değerlerini içermektedir. Her değer ile ilgili aynı başlıklar altında on altı (16) görev oluşturulmuştur. Görevleri öğrenciler istedikleri zaman, mekân ve internet aracından girerek tamamlamışlardır. Öğrenciler süreç içerisinde aktif bir rol almışlardır.

Görevlerle ilgili örnek uygulamalar ve tanıtımlar site içerisine konulmuştur. Ancak buna rağmen sorun yaşama ihtimallerine karşılık site içerisine iletişim bilgileri eklenmiştir.

Uygulama içerisindeki görevler, öğrencilerin gelişim düzeyleri dikkate alınarak belirlenmiştir. Metin okuma görevinde ilgili değerin kazanımlarını kapsayan hikâyeler ve hikâyelerle ilgili sorular verilmiş ve cevaplamaları istenmiştir. Slogan hazırlama görevinde öğrencilere değerlere sahip olduklarında ve olmadıklarında sahip olacakları karakter durumları hakkında bilgi verilip, buradan yola çıkarak örnek bir slogan verilip, kendilerinden de özgün sloganlar üretmeleri istenmiştir.

Fotoğraf yorumlama görevinde öğrencilere ilgili değerlerin kazanımlarını içeren fotoğraflar verilmiş ve fotoğraflardaki doğru ve yanlış durumları belirtilmesi istenmiştir. Video izleme ve yorumlama görevinde ilgili değerlerin içeriğini oluşturan videolar izletilmiş ve videolarla ilgili sorular sorulup, cevaplandırılması istenmiştir.

Drama uygulama görevinde öğrencilere ilgili değerlerin kazanımlarını içeren metinler verilmiş, öğrencilerden kendi aralarında bu metinleri okuyup, drama olarak canlandırmaları istenmiştir. Canlandırdıkları dramaları video kaydına alıp, sisteme yüklenmeleri sağlanmıştır. Ardından dramayla ilgili sorulara cevap vermeleri istenmiştir.

Şiir yazma görevinde değerlerle alakalı özgün şiirler yazmaları istenmiştir. Tanım yapma görevinde değerleri web üzerindeki kaynaklardan yararlanarak tanımlamaları ve tanımlarken kullandıkları kaynakçaları belirtmeleri istenmiştir. Güzel söz yazma görevinde değerlerle alakalı herkes tarafından tanınan kişilerin sözlerini yazmaları, bu sözü ve kişiyi neden tercih ettiklerini belirtmeleri istenmiştir. Kıssadan hisse görevinde, değerlerle ilgili 
bir hikâye verilmiş ve bu hikâyedeki ana karakterin yerinde olsalardı hangi durumları tercih edecekleri hakkında bilgi vermeleri istenmiştir.

Gazeteden haber bulma görevinde değerlerle alakalı web ortamından haber bulmaları ve buldukları haberin kaynaklarını belirtmeleri istenmiştir.

Örnek Şahsiyet (Kişi) gösterme görevinde öğrencilerden tanınmış ve yakın çevrelerinden dürüstlük ve adalet denilince akıllarına gelen kişileri nedenleriyle belirtmeleri istenmiştir.

Haydi fikrini söyle değerlerle ilgili ikilem cümleleri verilmiş ve öğrencilerden özgün bir cevap vermeleri istenmiştir. Kitap önerisi görevinde öğrencilerden dürüstlük ve adalet değerleri temalı kitaplar okumaları istenmiş, okudukları bu kitap hakkında bilgiler vermeleri, eğer bu kitabı arkadaşlarına da tavsiye ediyorlarsa bunu belirtmeleri istenmiştir.

Hikâye oluşturma görevinde değerlerin temalarını içeren, kendi gelişim düzeylerinde, kısa ve özgün hikâyeler yazmaları istenmiştir. Mini yarışma görevinde dürüstlük ve adalet değerleri ile ilgili mini testler hazırlanmış ve cevaplandırmaları istenmiştir. Atasözü bulalım görevinde dürüstlük ve adalet değerleriyle ilgili atasözleri bulmaları, anlamlarını belirtmeleri ve hangi durumlarda kullanmaları gerektikleri açılamaları istenmiştir.

\section{Araştırma Yöntemi}

$\mathrm{Bu}$ araştırmada WTDE programının sürecini betimlemek ve kullanılabilirliğini ortaya koymak amacıyla nicel ve nitel araştırma yöntemleri birlikte kullanılmıştır. Nicel kısımda "Değerlerle İlgili İkilem Formu" kullanılarak, öntest-sontest deney gruplu desene dayalı yarıdeneysel yöntem kullanılmıştır. Nitel kısımda ise "Yarı Yapılandırılmış Görüşme Formu" ile "Görev Değerlendirme Kontrol Listesi" kullanılarak veriler betimsel analiz kullanılarak açıklanmıştır.

Nicel Araştırma yöntemiyle elde edilen verilerin çözümlenmesinde, $\mathrm{N}$ sayısının küçüklüğü nedeniyle parametrik olmayan test istatistiklerinden Wilcoxon Testi kullanılmıştır (Büyüköztürk, 2011).

Nitel Araştırma yöntemiyle elde edilen verilerin çözümlenmesinde ise, içerik analizi ve görev analizi yapılmıştır.

Araştırma, İstanbul ilinde üst, orta ve alt düzey sosyo ekonomik düzey çocukların öğrenim gördüğü bir devlet okulunda gerçekleştirilmiş ve araştırma için 4-E sınıfından 10 öğrenci (5 kız-5 erkek) sürece dâhil edilmiştir.

Araştırma için seçilen grup ve ailelerine uygulamadan 2 hafta önce bilgilendirme toplantısı yapılmış, gereken izinler alınmış ve Değerlerle İlgili İkilem Formları her öğrenci için uygulanmıştır. Bu işlemlerin ardından, 7 Ocak 2013- 8 Mart 2013 Tarihleri arasında(4 hafta Dürüstlük değeri 
Sosyal Bilimler Dergisi 93

uygulaması, 4 hafta Adalet değeri uygulaması) araştırma grubuna Web Tabanlı Değerler Eğitimi programı uygulanmıştır. Uygulama süreci bittikten hemen sonra "Görev Değerlendirme Kontrol Listesi" kullanılarak öğrencilerin uygulama süreci içerisindeki verileri tespit edilmiştir, ayrıca "Yarı Yapılandırılmış Görüşme Formu" ile öğrencilerin uygulama ve uygulama süreci hakkında düşüncelerine ilişkin veriler kayıt altına alınmıştır. Burada hazırlanan sorulara verilen cevaplar içerik analizi ile analiz edilmiştir.

Uygulama süreci bittikten 2 hafta sonra ise "Değerlerle İlgili İkilem Formu" tekrar öğrencilere uygulanmış ve veriler kayıt altına alınmıştır.

Uygulamanın alana ve bu alandaki öğretmenlere alternatif bir yöntem olarak kullanılması amaçlanmıştır. Bu bağlamda Web Tabanlı Değerler Eğitimi uygulamasını, geleneksel değerler eğitimiyle karşılaştırıp, farkını ortaya koymak yerine, bu uygulamanın öğretmenlerin ve öğrencilerin yararlanabileceği bir modül olması hedeflenmiştir. Bu noktadan hareketle uygulamanın öğrenciler tarafından uygulanabilir olduğunu ölçmek adına sadece deney-kontrol grubu yerine çalışma grubundan yararlanılmıştır. Bu da çalışmamızın dürüstlük ve adalet değer seçimi, 12 hafta olan süresi ile birlikte 10 öğrencilik çalışma grubu seçimi araştırmamızın sinırlılıklarındandır.

\section{Bulgular ve Yorum}

WTDE dürüstlük ve adalet değerlerini kazandırmada etkili bir uygulama mıdır? problemi kapsamındaki veriler, "Görev Değerlendirme Kontrol Listesi" ve "Değerlerle İlgili İkilem Formu" ile toplanmış, analiz edilmiş ve yorumlanmıştır. Web ortamındaki değerlerle ilgili görevlerin öğrenciler tarafından başarıyla yerine getirilip getirilmediğini "Görev Değerlendirme Kontrol Listesiyle" görev analizi yapılıp, yorumlanmıştır.

Dürüstlük değeri görev analizinde; metin okuma ve soruları cevaplama, fotoğraf yorumlama, video izleme ve yorumlama, drama uygulama, tanım yapma, güzel söz yazma, gazeteden haber bulma, örnek şahsiyet (kişi) gösterme, haydi fikrini söyle, kitap önerisi, mini yarışma ve atasözü bulma görevlerinde, tüm öğrenciler başarılı olmuş, görevleri beklenen şartlara göre tamamlamışlardır. Ayrıca, şiir yazma ve hikâye oluşturma görevlerinde de öğrencilerin tamamı en az 1 puan alarak, beklenen şartları gerçekleştirerek görevlerini tamamlamışlardır.

Adalet değeri görev analizinde, metin okuma ve soruları cevaplama, slogan hazırlama, fotoğraf yorumlama, video izleme ve yorumlama, drama uygulama, tanım yapma, güzel söz yazma, gazeteden haber bulma, örnek şahsiyet (kişi) gösterme, haydi fikrini söyle, kitap önerisi, mini yarışma ve 
atasözü bulma görevlerinde, tüm öğrenciler başarılı olmuş, görevleri beklenen şartlara göre tamamlamışlardır. Ayrıca şiir yazma ve hikâye oluşturma görevlerinde de öğrencilerin tamamı en az 1 puan alarak, beklenen şartları gerçekleştirerek görevlerini tamamlamışlardır.

Görev Değerlendirme Kontrol Listesi" ile yapılan görev analizi sonucunda Web Tabanlı Değerler Eğitimi uygulamasının adalet ve dürüstlük değerini öğrencilere kazandırmada etkili olabileceğini söyleyebiliriz.

"Değerlerle İlgili İkilem Formu" aracılığıyla elde edilen verilerle de, öğrencilerin dürüstlük ve adalet değerleri temalı görevleri uygulama aşamasında tamamlanan görevlerle hedeflenen değerleri kazandırmadaki etkisi belirlenmeye çalışılmıştır. İkilem formundan elde edilen adalet değerine ilişkin uygulama öncesi ve sonrası değişim, dürüstlük değerine ilişkin uygulama öncesi ve sonrası değişim ve değer eğitimi sonrası toplam değişimi ortaya koymak amaciyla parametrik olmayan yöntemlerden Wilcoxon eşleştirilmiş iki örnek testi kullanılmıştır.

Tablo 1'de dürüstlük değerine ilişkin öğrencilerin ön test ve son test puanları arasındaki farka ilişkin bulgulara yer verilmiştir.

Tablo 1. Ön test-son test dürüstlük değeri puanlarının Wilcoxon eşleştirilmiş iki örnek testi sonuçları

\begin{tabular}{llllll}
\hline $\begin{array}{l}\text { Dürüstlük değeri } \\
\text { puanları ön test/son test }\end{array}$ & $\mathrm{N}$ & $\begin{array}{l}\text { Sira } \\
\text { Ort. }\end{array}$ & $\begin{array}{l}\text { Sıra } \\
\text { Toplamı }\end{array}$ & $\mathrm{Z}$ & $\mathrm{P}$ \\
\hline Negatif & 1 & 2 & 2 & $-2,615$ & .009 \\
Pozitif & 9 & 5,8 & 53 & & \\
Eşit & 0 & & & & \\
\hline
\end{tabular}

Tablo 1 incelendiğinde web tabanlı değerler eğitimi uygulamasına katılan öğrencilerin dürüstlük değer puanlarının uygulama öncesinde ve sonrasında anlamlı farklılık gösterdiği görülmektedir $(\mathrm{z}=-2,615 ; \mathrm{p}<.05)$. Bu bulgu web tabanlı değerler eğitimimin ilköğretim öğrencilerinin dürüstlüğe ilişkin değer algiları üzerinde anlamlı etkisi olduğu şeklinde yorumlanabilir.

Tablo 2'de adalet değerine ilişkin öğrencilerin ön test ve son test puanları arasındaki farka ilişkin bulgulara yer verilmiştir. 
Sosyal Bilimler Dergisi 95

Tablo 2. Ön test -son test adalet değeri puanlarının Wilcoxon eşleştirilmiş iki örnek testi sonuçları

\begin{tabular}{llllll}
\hline $\begin{array}{l}\text { Adalet değeri puanları } \\
\text { ön test/son test }\end{array}$ & $\mathrm{N}$ & $\begin{array}{l}\text { Sira } \\
\text { Ort. }\end{array}$ & $\begin{array}{l}\text { Sira } \\
\text { Toplamı }\end{array}$ & $\mathrm{Z}$ & $\mathrm{P}$ \\
\hline Negatif & 0 & 0 & 0 & $-2,814$ & .005 \\
Pozitif & 10 & 5,5 & 55 & & \\
Eşit & 0 & & & & \\
\hline
\end{tabular}

Tablo 2 incelendiğinde değerler eğitimi uygulamasına katılan öğrencilerin adalet değer puanları uygulama öncesinden ve sonrasında anlamlı farklılık gösterdiği görülmektedir $(\mathrm{z}=-2,814 ; \mathrm{p}<.05)$. Bu bulgu web tabanlı değerler eğitimimin ilköğretim öğrencilerinin adalete ilişkin değer algıları üzerinde anlamlı etkisi olduğu şeklinde yorumlanabilir.

Değerler eğitimi sonrası adalet ve dürüstlük alt boyutlarına ilişkin ikilem formundan elde edilen toplam puanın uygulama öncesi ve sonrası değişimi Tablo 3'te verilmiştir.

Tablo 3. Uygulama öncesi ve sonrası toplam puandaki değişime ilişkin Wilcoxon eşleştirilmiş iki örnek test sonuçları

\begin{tabular}{llllll}
\hline $\begin{array}{l}\text { İkilem formu toplam } \\
\text { puan ön test/son test }\end{array}$ & $\mathrm{N}$ & $\begin{array}{l}\text { Sira } \\
\text { Ort. }\end{array}$ & $\begin{array}{l}\text { Sira } \\
\text { Toplamı }\end{array}$ & $\mathrm{Z}$ & $\mathrm{P}$ \\
\hline Negatif & 0 & 0 & 0 & $-2,809$ & .005 \\
Pozitif & 10 & 5,5 & 55 & & \\
Eşit & 0 & & & & \\
\hline
\end{tabular}

Tablo 3 incelendiğinde değerler eğitimi uygulamasına katılan öğrencilerin ikilem formundan elde ettikleri puanlarının uygulama öncesinden ve sonrasında anlamlı farklılık gösterdiği görülmektedir ( $\mathrm{z}=-$ $2,809 ; \mathrm{p}<.05)$. Bu bulgu web tabanlı değerler eğitimimin ilköğretim öğrencilerinin değer algıları üzerinde anlamlı etkisi olduğunun göstergesi olarak yorumlanabilir.

Yukarıdaki elde edilen verilerden özetle, öğrencilerin belirlenen görevleri başarıyla tamamlamaları, ikilem formundaki elde edilen sonuçlara göre anlamlı fark çıması, WTDE'nin dürüstlük ve adalet değerini kazandırmada etkisi olabileceği ve WTDE'nin kullanılabilir olacağı şeklinde yorumlanabilir.

"WTDE hakkında öğrenci görüşleri nelerdir?" sorusu ile ilgili veriler "Yarı Yapılandırılmış Görüşme Formu" aracılığıyla toplanmış ve analiz 
edilmiştir. Öğrencilerin uygulanan ve katılım gösterdikleri Web Tabanlı Değerler Eğitimi uygulaması ile görüşleri ve uygulama ile ilgili veriler alınarak, elde edilen sonuçlar desteklenmiştir.

Öğrencilerin uygulanan ve katılım gösterdikleri Web Tabanlı Değerler Eğitimi uygulaması ile görüşleri ve uygulama ile ilgili veriler alınarak, böyle bir uygulamanın kullanılabilir bir yaklaşım olduğu ve böylece öğrenciler için alternatif bir yaklaşım olup olmayacağı belirlenmeye çalışılmıştır.

Uygulama süreci sonunda WTDE programını kullanan öğrencilerin tamamı ile görüşülerek uygulama kullanımı süresince geçirilen öğrenme yaşantıları ve uygulama ile ilgili görüşlerinin alınması için hazırlanan yarı yapılandırılmış bir görüşme formu aracılığı ile görüşmeler yapılmıştır. Uygulama süreci sonunda WTDE programını kullanan öğrencilerin tamamı ile görüşülerek uygulama kullanımı süresince geçirilen öğrenme yaşantıları ve uygulama ile ilgili görüşleri kayıt altına alınmıştır.

Katılımcıların görüşme formundaki sorulara verdikleri yanıtlara ilişkin, temsil edici örnekler aşağıda sunulmuştur.

Uygulamanın kullanımı, uygulamayı kullanma sürecindeki yaşadıkları deneyimler aldıkları yardımlar hakkında sorulan sorularda;

Öğrencilerin uygulamayı rahatlıkla kullandıkları ve uygulama sürecindeki yardımlardan memnun kaldıkları belirlenmiştir. Bu konuda Ö7:" Evet rahatlıkla kullandım. Şöyle anladım; uygulamalar kolaydı. Tarifleri vardı ayrıca." ve Ö9:" Evet yeterliydi. Her görevde bize konunun nasıl yapılacağ̆ tarif edildi. Ayrica sitede örnek uygulamalar vardı." şeklinde görüşlerini belirtmişlerdir.

Öğrenciler uygulamadan sıkılmadıkları, istedikleri zaman uygulamaya girmelerinin hoşlarına gittiği, WTDE uygulamasının kendilerine katkı ve avantaj sağladıkları belirtmişlerdir. Bu konuda Ö6:" "Haydi fikrini Söyle" adlı etkinlikte biraz sıkıldım. Çünkü yaparken zorlandım. Ama diğerlerini yaparken hiç sıkılmadım.", Ö1: "Hayır sıkılmadım o yüzden örnek veremem. " , Ö3: "Evet hoşuma gitti. Çünkü bazen uygulamayı yapamadığımda ertesi gün yapma şansım oluyor.", Ö5: ".Zamanı değerleri şeylerle geçirmemi sağladı. İnternet sayesinde eğitim ve öğretim hayatımıza evde de devam ettim. Dürüstlük ve adaleti evde de öğrenmiş oldum. ", Ö6: "Bu eğitim ile değerler eğitimini daha iyi anladım. Kısa yoldan öğrendim çoğu şeyi. Ayrıca internetten bir şeyler yapmak kendime öz güven kazandırdt." biçiminde görüşlerini belirtmişlerdir.

$\mathrm{Bu}$ bağlamda öğrencilerin WTDE uygulamasını severek kullandıklarını, süreç içerisindeki etkinliklerini keyif alarak yaptıklarını, uygulamanın kolaylıklarının ve bunun avantajlarının farkında olduklarını, 
Sosyal Bilimler Dergisi 97

uygulamanın olumsuz bir tarafının olmadığını, uygulamanın kendilerine katkılar sağladığını, WTDE günlük hayatta kullandıkları cihazlarla rahatlıkla erişebildiklerini ve diğer dersler içinde benzer uygulamaların hazırlamasının yararlı olacağını ortak görüş olarak ifade etmişlerdir.

\section{Sonuç ve Öneriler}

Araştırmadan elde edilen bulgulara göre ulaşılan sonuçlar aşağıda verilmiştir.

Dürüstlük ve adalet değerini kazandırmada öğrenciler Web Tabanlı Değerler Eğitimi Uygulamasındaki görevleri başarıyla yerine getirmiş ve süreç içerisinde uygulamayı benimsemişlerdir. Öğrenciler WTDE uygulamasına rahatlıkla uyum sağlayabilmiş ve sistem içerisinde sorun yaşamadan ve eğlenerek görevleri yapabilmişlerdir.

Öğrencilerin uygulamadan önce ve uygulamadan sonraki gelişimleri ve değişimleri ikilem formu ölçeğinden elde edilen bulgularla pozitif bir eğilimin olduğu görülmektedir. Bu bulgular göstermektedir ki, öğrenciler aldıkları bu eğitim ve uygulama ile birlikte, ilgili kazanımları edinilebilmektedir.

Öğrencilerin süreç içerisinde bulunurken memnuniyetleri, uygulamanın olumsuz bir tarafını görmemeleri, bu tür bir uygulamaya kolaylıkla adapte olduklarından dolayı öğrenciler tarafından alternatif bir yaklaşım olarak görülmektedir. Öğrencilerin WTDE uygulamasını olumlu ve kendileri için faydalı bir ortam olarak gördüğü ortaya çıkmıştır.

Yapılan çalışma; ilkokul 4. Sınıf öğrencileri için, 12 hafta süreyle yürütülen, araştırma grubunun 10 kişi olduğu, dürüstlük ve adalet değerinin çalışıldığı bir uygulamadır. Bu araştırma kapsamında daha farklı yaş gruplarıyla çalışılabilir, çalışma yapılacak örneklem sayısı artırılabilir, araştırma zamanı ve grubu farklı olabilir, farklı değerlerle de araştırmalar yapılabilir ve Web Tabanlı Değerler Eğitimi uygulaması ile geleneksel öğrenme ortamı karşılaştırılabilir.

$\mathrm{Bu}$ ve buna benzer uygulamalar daha kapsamlı planlanmalı, bu tür uygulamalardaki ön yargıları kırmak için veli, öğrenci, öğretmen, yönetici toplantıları yapılmalı, öğrencilerin bu tür uygulamalara her ortamda ulaşabilmesi için ücretsiz internet kampanyaları düzenlenmeli, bu tür uygulama ortamların her türlü internet aracıyla ulaşılabilir olması sağlanmalıdır. 


\section{Kaynakça}

ASLAN, M. (2011). İlköğretimde Karakter Eğitimi ve Öğrencilere Kazandırılması Gereken Değerler. Yayınlanmış Yüksek Lisans Tezi, Eskişehir Osmangazi Üniversitesi, Eğitim Bilimleri Enstitüsü, Eskişehir

AYDIN, M. Z. ve AKYOL, Ş. (2012). Okulda Değerler Ĕ̆itimi. Ankara: Nobel Yayın Dağıtım.

BALL, D. L. ve FORZANI, F. M. (2009). "The work of Teaching and the Challenge for Teacher Education", Journal of Teacher Education, Cilt:60, Sayı:5,2009,s. 497-511.

BALTACI, M. ve AKPINAR, B. (2011). Web Tabanlı Öğretimin Öğrencilerin Akademik Başarısına Etkisi. Fırat Üniversitesi Sosyal Bilimler Dergisi, 21(1), 77-88.

BÜYÜKÖZTÜRK, Ş. (2011). Sosyal Bilimler Veri Analizi El Kitabı (13. Basım). Ankara: Pegem Akademi Yayınevi

ÇAĞLAYAN, A. (2013). Ahlak Pusulası Ahlak ve Değerler Eğitimi (2. Basım). İstanbul: Dem Yayınları.

EKŞİ H. ve KATILMIŞ, A. (2011). Karakter Eğitimi El Kitabı. Ankara: Nobel Yayın Dağıtım.

ERDEMIR, M. ve İNGEÇ KANDİL, Ş. (2014). Fizik Eğitiminde Web Tabanlı Zeki Öğretim Sisteminin (ZÖS) Başarıya Etkisi. Eğitim ve Öğretim Araştırmaları Dergisi. 1(3), 289-298.

GÜNDAŞ, A., KURTULMUŞ, M. ve TÖSTEN, R. (2014). İlköğretim 1. Kademe Öğretmenlerinin Değerler Eğitimi Sürecinde Karşılaştıkları Sorunlar. Değerler Eğitimi Dergisi, 12, 281-305.

MEB (2010). İlköğretim (4, 5, 6, 7 ve 8. Sınıflar) Din Kültürü ve Ahlak Bilgisi Programı. Ankara: MEB Yayınları.

MOĞUL, S. (2012). Mehmet Akif Ersoy'un Safahat İsimli Eserinin Türkçe Eğitimi ve Değerler Eğitimi Açısından İncelemesi, Yayınlanmamış Yüksek Lisans Tezi, Erciyes Üniversitesi, Eğitim Bilimleri Enstitüsü, Erciyes Üniversitesi, Eğitim Bilimleri Enstitüsü, Kayseri

OLADIPO, S. E. (2009). "Moral Education of the Child: Whose Responsibility?" J Soc Sci, Cilt:20, Sayı:2, 2009,s. 149-156.

ORAL, B. ve KENANOĞLU, R. (2012). Web Tabanlı Uzaktan Eğitim Sistemlerinin Öğrenci Başarısına ve Bilgisayara Yönelik Tutumlarına Etkisi. Elektronik Eğitim Bilimleri Dergisi. 2(1), 58-67.

ÖĞRETICİ, B. (2011). İlköğretim 6. Sınıf Sosyal Bilgiler Derslerinde Değerler Eğitimine Yönelik Uygulamaların Etkililiğinin Araştırılması. Yüksek Lisans Tezi, Sakarya Üniversitesi, Eğitim Bilimleri Enstitüsü, Sakarya. 
SANDERSE, W. (2013). "The meaning of role modelling in moral and character education" , Journal of Moral Education. Cilt:42, Sayı:1, 2013, s.28-42.

TÜYSÜZ, C. ve AYDIN, H. (2007). Web Tabanlı Öğrenmenin İlköğretim Okulu Düzeyindeki Öğrencilerin Tutumuna Etkisi. Pamukkale Üniversitesi Eğitim Fakültesi Dergisi, 22(2), 73-84.

YAMAN, E. (2012). Değerler Eğitimi. Ankara: Akçă̆ Yayınları.

YENIAAD, M. (2006). Uzaktan Eğitimde Kullanılmak Üzere Web Tabanlı Bir Portal Yazılımı Geliştirme. Yayınlanmamış Yüksek lisans tezi, Çukurova Üniversitesi, Sosyal Bilimler Enstitüsü, Adana. 
K.KARAMAN, İ.AKGÜL 100 